\title{
Central Peptidergic Neurons Are Hyperactive during Collateral Sprouting and Inhibition of Activity Suppresses Sprouting
}

\author{
John A. Watt, ${ }^{1}$ Christopher W. Moffet, ${ }^{1}$ Xinrong Zhou, ${ }^{1}$ Sonja Short, ${ }^{1}$ James P. Herman, ${ }^{3}$ and \\ Charles M. Paden ${ }^{1,2}$ \\ 1Department of Biology and 2WWAMI Medical Program, Montana State University, Bozeman, Montana 59717-0346, and \\ ${ }^{3}$ Department of Anatomy and Neurobiology, University of Kentucky Medical Center, Lexington, Kentucky 40536
}

Little is known regarding the effect of chronic changes in neuronal activity on the extent of collateral sprouting by identified CNS neurons. We have investigated the relationship between activity and sprouting in oxytocin (OT) and vasopressin (VP) neurons of the hypothalamic magnocellular neurosecretory system (MNS). Uninjured MNS neurons undergo a robust collateral-sprouting response that restores the axon population of the neural lobe (NL) after a lesion of the contralateral MNS (Watt and Paden, 1991). Simultaneously, lesioned rats develop chronic urinary hyperosmolality indicative of heightened neurosecretory activity. We therefore tested the hypothesis that sprouting MNS neurons are hyperactive by measuring changes in cell and nuclear diameters, OT and VP mRNA pools, and axonal cytochrome oxidase activity (COX). Each of these measures was significantly elevated during the period of most rapid axonal growth between 1 and 4 weeks after the lesion, con-

Collateral sprouting is now known to occur in a variety of neuronal populations within both the mature mammalian PNS and CNS. However, little is known about the factors that determine the extent of collateral sprouting in specific situations. A fundamental question concerns the influence of neuronal activity. Various forms of neuronal plasticity are now known to be activity dependent (Theodosis and Poulain, 1993; Ben-Ari, 1995; Chen and Tonegawa, 1997), but it remains unclear to what extent the level of activity within specific neuronal populations may affect their capacity to undergo collateral sprouting.

In pioneering studies of the effects of impulse activity on collateral sprouting of peripheral nociceptive fibers into denervated skin, brief stimulation of the nerve before isolation of the target field reduced the latency of the sprouting response (Nixon et al., 1984; Diamond et al., 1992), but repeated stimulation after the isolation procedure had no effect on the ultimate extent of sprouting (Diamond et al., 1992). Collateral sprouting by the central processes of sensory neurons may also occur, and this response can be enhanced by concurrent damage to the peripheral axon that acts to induce regenerative metabolic processes (Molander et al., 1988; McMahon and Kett-White, 1991; Murray, 1993). However, peripheral damage would also be expected to reduce ongoing electrical activity in the neuron. Consistent with

\footnotetext{
Received July 24, 1998; revised Dec. 9, 1998; accepted Dec. 14, 1998.

This research was supported by National Institutes of Health Grants NS32507 and RR11795. We wish to thank C. M. Dolgas, Monique Mitchell, and Stacie Erickson for skilled technical assistance.

Correspondence should be addressed to Dr. Charles M. Paden, Department of Biology, Montana State University, Bozeman, MT 59717-0346.

Copyright (C) 1999 Society for Neuroscience $0270-6474 / 99 / 191586-13 \$ 05.00 / 0$
}

firming that both OT and VP neurons are hyperactive while undergoing collateral sprouting. In a second study the hypothesis that chronic inhibition of neuronal activity would interfere with the sprouting response was tested. Chronic hyponatremia $(\mathrm{CH})$ was induced $3 \mathrm{~d}$ before the hypothalamic lesion and sustained for 4 weeks to suppress neurosecretory activity. $\mathrm{CH}$ abolished the lesion-induced increases in OT and VP mRNA pools and virtually eliminated measurable COX activity in MNS terminals. Counts of the total number of axon profiles in the NL revealed that $\mathrm{CH}$ also prevented axonal sprouting from occurring. These results are consistent with the hypothesis that increased neuronal activity is required for denervation-induced collateral sprouting to occur in the MNS.

Key words: collateral sprouting; activity dependent; neurohypophysis; supraoptic nucleus; magnocellular neurosecretory system; chronic hyponatremia; oxytocin; vasopressin; hypothalamus

this interpretation, upregulation of the growth-associated protein GAP-43 in central sensory axons after lesions of the sciatic nerve occurs independently of nerve stimulation (Woolf et al., 1990). Thus the available evidence suggests that collateral sprouting by the central axons of peripheral sensory neurons is not activity dependent.

Within the brain, global increases in neuronal activity associated with both human epilepsy (Represa et al., 1990; Mathern et al., 1995; Prince et al., 1997) and either kindling stimulation (Sutula et al., 1988; Cavazos et al., 1991; Stringer et al., 1997) or kainate-induced seizure activity in rat limbic circuits (Represa et al., 1994, 1995; Stringer et al., 1997) have been shown to correlate with aberrant sprouting of mossy fiber axons to form recurrent collaterals onto dentate granule cells (Dudek and Spitz, 1997), but other branches of the same axons that terminate on CA3 pyramidal neurons apparently do not sprout (Represa et al., 1995). In addition, induction of seizures was found to inhibit collateral sprouting of cholinergic afferents in the deafferented dentate gyrus (Steward, 1994). Thus, although studies of hippocampal plasticity indicate that widespread increases in neuronal activity can influence collateral sprouting, a direct relationship between the level of activity of the sprouting neuron itself and the extent of axonal growth has not yet been established.

The magnocellular neurosecretory system (MNS), consisting of the oxytocin (OT) and vasopressin (VP) neurons located in the supraoptic (SON), paraventricular (PVN), and accessory hypothalamic nuclei and their projections to the neural lobe (NL) of the pituitary gland, offers a simplified model in which to investigate the relationship between neuronal activity and collateral 
axonal sprouting in central peptidergic neurons. We have reported previously that after unilateral destruction of MNS axons by a hypothalamic lesion, the uninjured MNS neurons in the contralateral hypothalamus undergo a robust collateral-sprouting response that restores the axon population of the NL to normal within $90 \mathrm{~d}$ (Watt and Paden, 1991). Lesioned rats also develop chronic urinary hyperosmolality accompanied by decreased urinary volume and water intake (Watt and Paden, 1991), suggesting that an increase in neurosecretory activity occurred simultaneously with collateral sprouting. The first aim of the present studies was therefore to test the hypothesis that both OT and VP neurons are hyperactive while undergoing collateral sprouting. In addition, the osmosensitivity of the MNS makes it possible to alter the activity of OT and VP neurons on a long-term basis. As our second aim, we have therefore used a chronic hyponatremia (CH) paradigm (Verbalis and Drutarosky, 1988) to determine whether sustained inhibition of neuronal activity inhibits collateral sprouting by OT and VP neurons.

\section{MATERIALS AND METHODS}

Surgical procedures. All experimental protocols were approved by the Montana State University Institutional Animal Care and Use Committee, and all applicable guidelines from the National Institutes of Health Guide for the Care and Use of Laboratory Animals were followed. Male Holtzman albino rats (bred from stocks originally obtained from Harlan Sprague Dawley, Indianapolis, IN) were maintained under a 12:12 hr light/dark cycle with tap water and lab chow available ad libitum in the Montana State University Animal Resource Center (Bozeman, MT), an American Association for Accreditation of Laboratory Animal Careaccredited facility. Rats were $35 \mathrm{~d}$ of age when a unilateral hypothalamic knife cut of the hypothalamo-neurohypophysial tract was made as described previously (Watt and Paden, 1991). Only those animals in which complete unilateral transection of the hypothalamo-neurohypophysial tract was histologically verified were included in these studies. Shamlesioned controls were prepared under identical conditions except that the knife did not penetrate the hypothalamus.

Tissue preparation for ultrastructural analysis. All reagents were obtained from Sigma (St. Louis, MO) unless otherwise indicated. Animals were perfused with $2 \%$ glutaraldehyde (Ted Pella, Redding, CA) plus $4 \%$ paraformaldehyde (Ted Pella) in $0.1 \mathrm{M} \mathrm{NaPO}_{4}, \mathrm{pH} 7.4$, under ether anesthesia. Each NL was removed intact and post-fixed by immersion at $4^{\circ} \mathrm{C}$ overnight, followed by secondary fixation in $4 \% \mathrm{OsO}_{4}$ (Ted Pella) for $4 \mathrm{hr}$ at room temperature. Individual NLs were dehydrated through increasing concentrations of ethanol to propylene oxide (Ted Pella), rinsed repeatedly in 100\% Epon/Araldite (50:50, v/v; Ted Pella), and vacuum infiltrated overnight before polymerization at $60^{\circ} \mathrm{C}$. Flat Beem capsule molds were used with the rostral pole of the NL positioned at the tip of the capsule. Serial $1 \mu \mathrm{m}$ coronal sections were collected through the entire NL with each 10th section mounted in series on glass microscope slides and counterstained with toluidine blue for measurement of the total cross-sectional area of the NL using the MCID M4 Image Analysis System (Imaging Research, St. Catherines, Ontario, Canada). Three sets of silver-gold ultrathin sections were collected at $300 \mu \mathrm{m}$ intervals, representing the rostral, middle, and caudal portions of the NL. After being mounted on 400 mesh copper grids, sections were counterstained with uranyl acetate and Reynold's lead citrate in an LKB Ultrastainer and viewed on a Zeiss TEM $10 \mathrm{C}$ at $40-60 \mathrm{kV}$.

Quantification of axon numbers. Three adjacent grid squares chosen at random were photographed at $5000 \times$ from each of the left, right, and central one-third of each NL cross section, giving a total of nine sampled fields from each of three NL cross sections per animal. After photographic enlargement to $13,500 \times$, an unbiased counting frame was positioned over each micrograph (Gundersen, 1977), and every axon profile, except those touching the exclusion sides, was counted using the presence of neurosecretory vesicles and/or neurofilaments to distinguish axon profiles from glial processes. Personnel performing the axon counts were unaware of the experimental design. The areal density (total number of axon profiles per square micrometer) was then calculated for the left, right, and central regions of each of the three cross sections of the NL. No significant differences were found between different regions in any group, permitting a single mean value to be calculated for each cross section. The total number of axons in each cross section was then estimated by multiplying the mean areal density by the total crosssectional area determined from the adjacent $1 \mu \mathrm{m}$ section as described above. In this manner the number of axon profiles was estimated separately for the rostral, middle, and caudal regions of the NL of each animal independently of any denervation-induced changes in the size of the NL. No significant differences in the number of axons were observed between the three regions of the NL in any group, permitting a single mean value to be calculated for each animal.

Induction of chronic hyponatremia. The $\mathrm{CH}$ protocol developed by Verbalis and Drutarosky (1988) was used to maintain a state of chronic plasma hypo-osmolality. Three days before surgery, dry lab chow and water were replaced with concentrated, nutritionally complete liquid diet (Bio-Serv, Frenchtown, NJ). The liquid diet served as the sole source of both nutritional and water requirements throughout the postsurgical period (mean body weight of both lesioned and sham-lesioned groups declined $20 \mathrm{gm}$ during the first week after induction of $\mathrm{CH}$ and then increased $95 \mathrm{gm}$ over the next 3 weeks). Osmotic pumps with a $14 \mathrm{~d}$ infusion period (Alza, Palo Alto, CA) were implanted subcutaneously immediately after the hypothalamic knife cut or sham lesion. Each pump contained the VP analog desmopressin acetate (Rhone-Poulenc Rorer, Ft. Washington, PA) at $4.0 \mathrm{ng} / \mu \mathrm{l}$ in $0.05 \mathrm{M}$ sterile $\mathrm{NaCl}$. To ensure immediate delivery of desmopressin at the time of implantation, we primed each pump by a $4 \mathrm{hr}$ incubation in sterile $0.15 \mathrm{M} \mathrm{NaCl}$ at $37^{\circ} \mathrm{C}$. Those animals sustained on desmopressin for $28 \mathrm{~d}$ received a replacement pump on postlesion day 14 under Metofane anesthesia (Mallinckrodt, Mundelein, IL).

Plasma collection and analysis. Plasma osmolality was determined for each animal at weekly intervals through the first 4 weeks after surgery. Blood samples were collected either by tail vein puncture under light Metofane anesthesia or from the trunk at death, transferred to a Microtainer plasma separator tube (Becton Dickinson, Cockeysville, MD), and centrifuged, and the plasma was stored at $4^{\circ} \mathrm{C}$ until analysis. Plasma osmolality was then determined using a model 5500 vapor pressure osmometer (Wescor, Salt Lake City, UT). Plasma sodium and potassium concentrations were also determined in the 1 and 4 week blood samples using a Dupont (Billerica, MA) Dimension-AR plasma analyzer at the Montana State Veterinary Diagnostic Laboratory at Montana State University (Bozeman, MT).

Cellular morphometry. Animals were transcardially perfused with $4 \%$

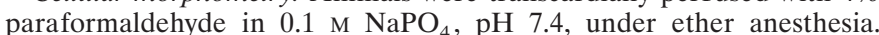
Brains were removed, blocked, and dehydrated for paraffin embedment. $\mathrm{OT}$ and VP neurons were stained on $6 \mu \mathrm{m}$ sections using the $\mathrm{ABC}$ peroxidase immunocytochemical procedure as described previously (Moffett and Paden, 1994) with, as primary antisera, either rabbit anti-rat oxytocin (1:5000; Chemicon, Temecula, CA) or rabbit antiserum recognizing a synthetic polypeptide consisting of the $14 \mathrm{C}$-terminal amino acids of rat vasopressin-neurophysin (antiserum Thr, prepared under National Institutes of Health Grant AM16166 and donated by Dr. Alan G. Robinson, University of California at Los Angeles, Los Angeles, CA). Cross-sectional areas of cell nuclei and somata in the intact contralateral SON were measured by tracing microscopic images directly onto a digitizing tablet via a drawing tube. Areas were calculated using software developed by Dr. Steven Young of the University of California at San Diego (San Diego, CA). Fifty magnocellular somata and their respective cell nuclei were measured in the SON contralateral to the hypothalamic lesion in each animal by personnel unaware of the experimental design ( $n=4-8$ per group). Only neurons possessing a distinct cell boundary, a clearly defined nuclear envelope, and a distinct nucleolus were measured. Measurements in the SON were collected from within both the principle and retrochiasmatic divisions.

In situ hybridization. Rats were decapitated under Metofane anesthesia, and the brains and pituitaries were quickly removed and frozen on dry ice. Ten micrometer serial cryosections were then cut through the entire SON and PVN and thaw mounted on Superfrost Plus glass slides (Fisher Scientific, Houston, TX). Sections were stored at $-80^{\circ} \mathrm{C}$ until immersion fixed for $30 \mathrm{~min}$ in $4 \%$ buffered paraformaldehyde and deproteinated with proteinase $\mathrm{K}(0.1 \mu \mathrm{g} / \mathrm{ml})$ for $15 \mathrm{~min}$ at $37^{\circ} \mathrm{C}$ in preparation for in situ hybridization using ${ }^{35} \mathrm{~S}$-labeled cRNA probes recognizing nonhomologous sequences within exon $\mathrm{C}$ of the VP and OT mRNAs (Sherman et al., 1988; Herman et al., 1991). Slides were rinsed in nanopure water, washed in $0.1 \mathrm{M}$ triethanolamine, $\mathrm{pH} 8.0$, for $1 \mathrm{~min}$, incubated for $10 \mathrm{~min}$ in $0.25 \%$ acetic anhydride in $0.1 \mathrm{M}$ triethanolamine, and then rinsed in $2 \times$ SSC and dehydrated in graded alcohols. The labeled probe was added to a hybridization buffer containing $50 \%$ for- 
mamide (Amresco, Solon, $\mathrm{OH}$ ) and $20 \mathrm{~mm}$ DTT and was denatured at $70^{\circ} \mathrm{C}$ for $5 \mathrm{~min}$, and $50 \mu \mathrm{l}\left(1 \times 10^{6} \mathrm{cpm}\right)$ of diluted probe was then applied to each slide. Subsequently the slides were coverslipped, placed in moistened chambers, and incubated overnight at $55^{\circ} \mathrm{C}$. After hybridization, coverslips were removed in $2 \times \mathrm{SSC}$, and the slides were rinsed in fresh $2 \times$ SSC for $10 \mathrm{~min}$, treated with RNase A $(100 \mu \mathrm{g} / \mathrm{ml})$ for $30 \mathrm{~min}$ at $37^{\circ} \mathrm{C}$, transferred to fresh $2 \times \mathrm{SSC}$, and then rinsed three times in $0.2 \times$ SSC (10 min per wash), followed by a $1 \mathrm{hr}$ wash in $0.2 \times \mathrm{SSC}$ at $65^{\circ} \mathrm{C}$. Slides were then dehydrated in graded alcohols, dried at room temperature, exposed for $7 \mathrm{~d}$ to BioMAX film (Kodak, Rochester, NY), and subsequently dipped in Kodak NTB2 emulsion (diluted 1:1 in deionized water). Emulsion autoradiographs were exposed for $30 \mathrm{~d}$ and then developed in Kodak D-19 developer $\left(2 \mathrm{~min} ; 16^{\circ} \mathrm{C}\right)$, dehydrated, and coverslipped.

Image analysis was performed on emulsion-dipped autoradiographs of sections through the rostral hypothalamus. After coding of sections for blind analysis and digitization using NIH Image software (courtesy of W. Rasband, National Institutes of Health), the SON were delineated on the basis of signal localization and adjacent Nissl-stained series and gray level measurements obtained from these areas using a manual sampling mode. A background gray level measurement was taken over a nonhybridized area of hypothalamus and subtracted from each sample value. A mean value for each animal was determined from three to six sections through the SON and used in the subsequent analysis of group effects.

Cytochrome oxidase histochemistry. Pituitary tissue from the same animals killed for in situ hybridization was processed for cytochrome oxidase (COX) activity using a method modified from previous reports (Seligman et al., 1968; Wong-Riley, 1976; Adams, 1981). Ten micrometer cryosections, thaw mounted on Superfrost Plus slides, were immersed in a reaction mixture containing $200 \mathrm{mg} / 1$ 3,3'-diaminobenzidine, $50 \mathrm{mg} / 1$ glucose, $5 \mathrm{mg} / 1$ cobalt chloride (J. T. Baker Chemical Company, Phillipsburg, NJ), $5 \mathrm{mg} / \mathrm{l}$ nickelous ammonium chloride (J. T. Baker Chemical Company), and $100 \mathrm{mg} / 1$ cytochrome $\mathrm{C}$ in Trizma buffer $(0.05 \mathrm{M}), \mathrm{pH}$ 7.4 , for $30 \mathrm{~min}$ at $37^{\circ} \mathrm{C}$. The reaction was quenched by sequential washes in Trizma buffer, followed by immersion fixation of the sections in $4 \%$ buffered formalin for $10 \mathrm{~min}$ at $4^{\circ} \mathrm{C}$. Sections were then dehydrated through increasing concentrations of ethanol, cleared in xylene, and coverslipped. Each staining run contained sections from multiple experimental groups to minimize any effect of between-run variability on group means, and sections were coded for blind analysis. Quantification of COX staining was performed using the MCID M4 Image Analysis System. After the illumination level was adjusted to standardize the background optical density of each slide, the proportional area of the NL with optical density greater than background was measured on a minimum of nine sections per subject. This measure was found to provide a more-sensitive and less-variable estimate of COX activity than did the mean optical density.

Statistical analysis. One- and two-way ANOVAs were performed using the General Linear Model module of the MSUSTAT Statistical Analysis Package developed by Dr. Richard E. Lund of Montana State University (Bozeman, MT). Post hoc tests of the significance of group differences were performed using the protected LSD method.

\section{RESULTS}

In the initial set of experiments the hypothesis that both OT and VP neurons are hyperactive while undergoing collateral sprouting was tested by measuring changes in cell and nuclear diameters, OT and VP mRNA pools, and axonal COX activity in sprouting neurons. In the second set of experiments the hypothesis that chronic inhibition of neuronal activity would interfere with the sprouting response was tested. Sustained reduction in the activity of OT and VP neurons was induced by $\mathrm{CH}$, and the effects of this treatment on OT and VP mRNA pools and on axonal COX activity and the extent of collateral sprouting were determined.

\section{Lesion-induced collateral sprouting in the NL}

The location of the unilateral hypothalamic knife cut used to hemisect the MNS is shown in Figure 1. We have demonstrated previously that magnocellular axons arising from both the PVN and SON as well as from the accessory nuclei ipsilateral to the knife cut are transected by the lesion and do not regenerate,

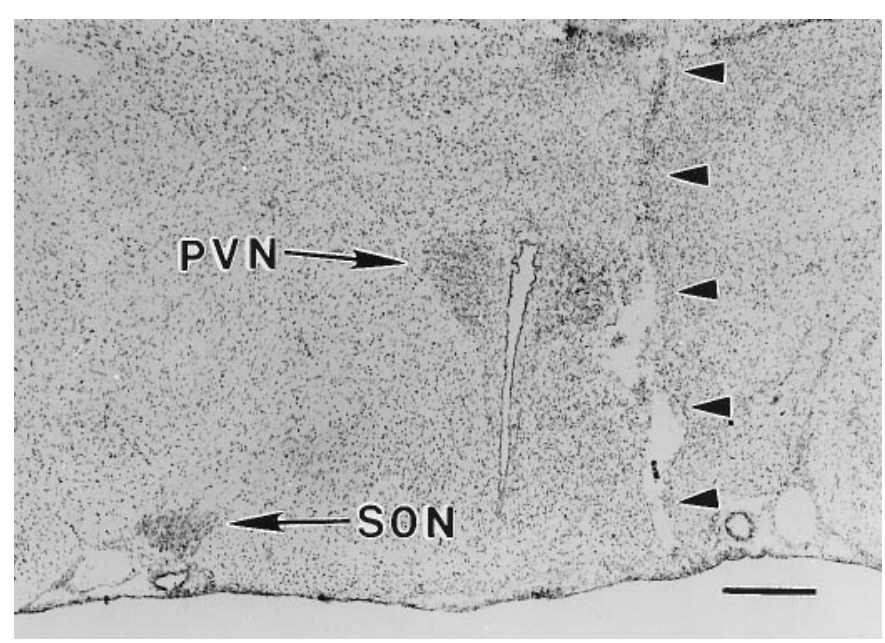

Figure 1. The hypothalamic knife cut (arrowheads) used to achieve unilateral destruction of the MNS is visible in this micrograph of a coronal section through the hypothalamus at the level of the PVN and SON (10 d postlesion animal). The knife cut completely severs the axons forming the right half of the hypothalamo-neurohypophysial tract, including those arising from the magnocellular neurons of the PVN that follow a ventral-lateral course before turning medially to enter the median eminence (Silverman and Zimmerman, 1983). The SON ipsilateral to the cut has degenerated and is barely visible. Axons arising from the contralateral SON and PVN (arrows) undergo collateral sprouting in the NL subsequent to the lesion (Watt and Paden, 1991). Scale bar, $500 \mu \mathrm{m}$.

making it possible to quantify the extent of collateral sprouting from intact contralateral MNS neurons by counting the number of axon profiles in coronal ultrathin sections of the NL (Watt and Paden, 1991). In those studies we used the number of axonal profiles in randomly chosen sample fields as an estimate of the total axonal population of the NL, whereas in the present experiments we have extended those findings by (1) increasing the number of fields to provide a systematic sampling of the entire NL and (2) multiplying each estimate of the areal density of axons by the corresponding cross-sectional area of the NL to arrive at estimates of the total number of axons that are corrected for changes in the size of the NL.

The electron micrographs in Figure 2 are representative of those used for axon counting (except that counts were made from micrographs at twice the enlargement shown), and they illustrate the typical changes in the ultrastructure of the NL seen at 1 and 4 weeks after the lesion. Note that almost all neurosecretory axons are cut in cross section and are identifiable by the presence of secretory vesicles and/or neurofilaments. A marked decrease in the areal density of axonal profiles with a concomitant increase in extracellular space was apparent by 1 week after the lesion (Fig. $2 B$ vs $A$ ), but these changes were almost completely reversed by 4 weeks as rapid axonal sprouting occurred (Fig. 2C).

To quantify the sprouting response, we counted the total number of axonal profiles in 27 electron micrographs representing nine sites distributed throughout the medial-lateral and rostralcaudal extent of the NL in each subject (see Materials and Methods). No statistically significant differences were observed between different locations within any group, permitting the data to be pooled to yield one value per subject. In addition, the absence of any differences in the extent of axonal sprouting between the central and lateral regions of the NL indicates that OT and VP neurons participate similarly in the sprouting response, because VP axons predominate in the center and OT in the periphery of the rat NL (Van Leeuwen et al., 1979). 

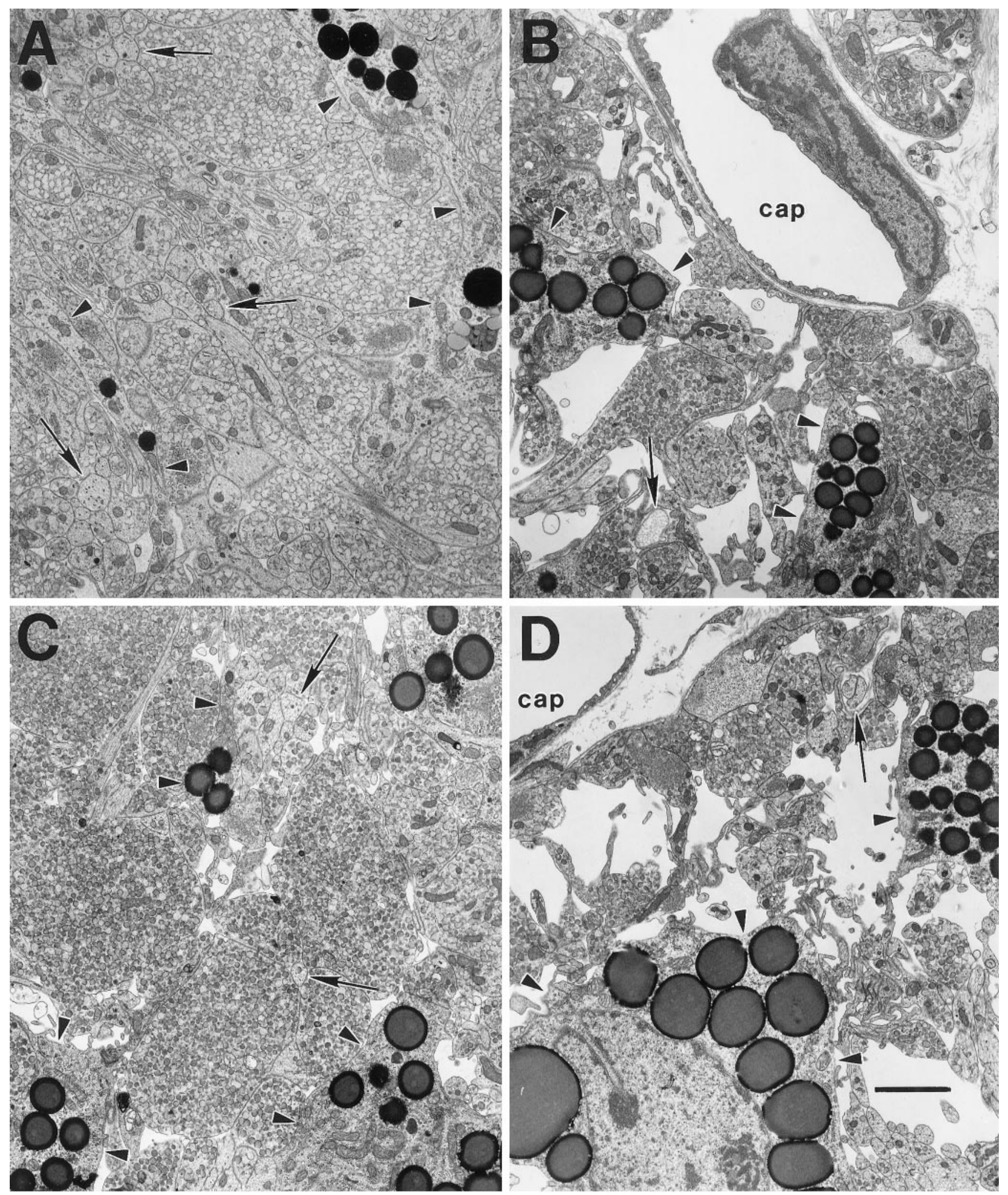

Figure 2. The typical ultrastructure of the NL is shown in electron micrographs of coronal sections from 1 week postsurgical intact control $(A), 1$ week postlesion $(B), 4$ week postlesion $(C)$, and 4 week chronic hyponatremic postlesion $(D)$ animals. $A$, The intact NL is characterized by densely packed neurosecretory axons, frequently filled with neurosecretory vesicles, interspersed with glial (pituicyte) processes (arrowheads) that often contain osmiophilic lipid inclusions. Smaller axonal profiles lacking vesicles are identifiable by the presence of neurofilaments (arrows). B, By 1 week after the hypothalamic lesion, the number of axons is dramatically reduced, and the amount of extracellular space is substantially increased. $C$, At 4 weeks after the lesion, these degenerative changes have been largely reversed as collateral sprouting has returned the number of axon profiles to near normal levels. $D$, In contrast, the axon population does not recover in rats maintained under $\mathrm{CH}$ during the 4 week postlesion interval, and a substantial amount of extracellular space remains. cap, Capillary lumen. Scale bar, $2 \mu \mathrm{m}$. 


\section{Collateral Sprouting of MNS Axons in the Neural Lobe}

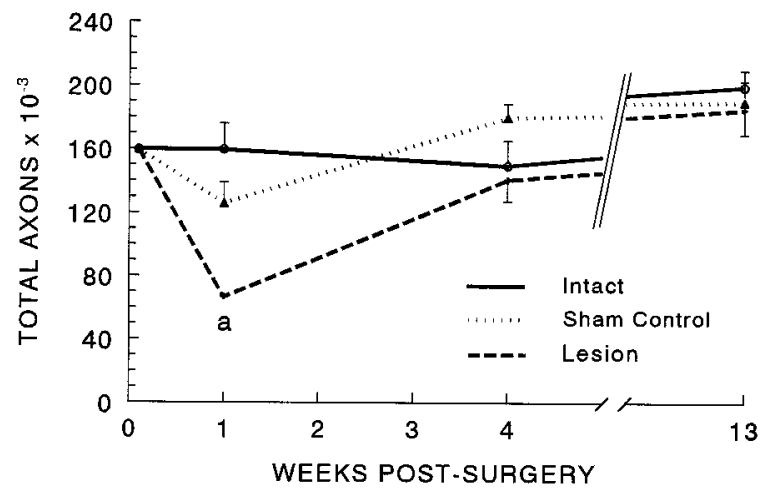

Figure 3. Determination of the total number of axonal profiles in the NL revealed the presence of robust collateral sprouting in lesioned animals. The number of axons was significantly reduced 1 week after the unilateral hypothalamic lesion ( $a$, less than intact control, $p<0.01$; less than sham-lesioned control, $p<0.05)$. By 4 weeks after surgery, collateral sprouting restored the axon population in the lesioned group to normal, and there were no significant differences between any groups at either 4 or 13 weeks. The apparent maturational increase in total axonal profiles between 4 and 13 weeks is statistically significant when the data from all three groups are pooled (see Results). To obtain these data, we estimated the total number of axonal profiles in coronal sections of the NL by determining the areal density of axons in three electron micrographs from each of nine sites distributed throughout the medial-lateral and rostralcaudal extent of the NL in each subject. Areal densities were then multiplied by the corresponding cross-sectional area of the NL at each level to obtain the total number of axons, and a single average value was calculated for each subject (see Materials and Methods). Each data point and error bar represent the mean and SEM of five to nine animals. No data were collected at the time 0 point, which is set equal to the 1 week intact control value simply to illustrate the effect of surgery on each experimental group.

The number of axonal profiles in the NL was reduced by approximately one-half at $7 \mathrm{~d}$ after the lesion (one-way ANOVA, $F=11.26$; df $=2,13 ; p<0.002$; see Fig. 3 for comparisons between individual groups). A much smaller and statistically nonsignificant decline in the number of axons was seen in shamlesioned controls at this time. At 4 weeks after surgery, a marked recovery in the total number of axonal profiles in the NL was evident in the lesioned animals, with the number of axons reaching $94 \%$ of the value measured in intact controls (Fig. 3). These data indicate that a robust sprouting response was elicited in the uninjured contralateral MNS neurons by the hypothalamic lesion. The number of axons was also increased somewhat in shamlesioned controls at 4 weeks, but this change was not statistically significant. By 13 weeks after surgery, the total number of axonal profiles in the NL was indistinguishable in intact, sham-lesioned, and lesioned groups (Fig. 3), indicating that collateral sprouting by uninjured magnocellular axons had completely compensated for the loss of terminals caused by hemisection of the hypothalamo-neurohypophysial tract.

In addition, the total number of axons in every group was greater at 13 weeks ( $125 \mathrm{~d}$ of age) than at 4 weeks ( $63 \mathrm{~d}$ of age) after surgery, suggesting that axonal sprouting continues to occur during maturation of the NL in intact as well as in lesioned rats. Although these age-related increases were not significant within any of the three individual treatment groups, pooling the values for intact, lesioned, and sham-lesioned animals revealed a signif- icant increase of $24 \%$ in the total number of axons in the NL between 63 and $125 \mathrm{~d}$ of age $(t=2.61 ; p<0.02)$.

\section{Hypertrophy of OT and VP neurons during collateral sprouting}

Hypertrophy of MNS neurons and cell nuclei is associated with sustained increases in neurosecretory activity induced by osmotic stimulation (Peterson, 1966; Morris and Dyball, 1974). We therefore measured the cross-sectional area of OT and VP neurons and their cell nuclei in the SON at different times after the hypothalamic lesion to determine whether similar increases in cellular and nuclear size were correlated with the collateral-sprouting response. Measurements were confined to the SON contralateral to the hypothalamic lesion (termed the sprouting SON) because, unlike the magnocellular neurons of the PVN that may have multiple projections, virtually every neuron in the rat SON projects exclusively to the NL (Silverman and Zimmerman, 1983).

As shown in Figure 4, $A$ and $B$, both OT and VP neurons were hypertrophied during the first $30 \mathrm{~d}$ after the lesion when the collateral-sprouting response was most vigorous. OT neuronal size was significantly increased in lesioned versus sham-lesioned groups (two-way ANOVA, $F=8.41$; $\mathrm{df}=1,24 ; p<0.01$ ), with the largest increase over controls $(33 \%)$ occurring at $10 \mathrm{~d}$ after surgery. VP neuronal size was also significantly increased by hypothalamic lesions compared with sham lesions (two-way ANOVA, $F=8.16$; df $=1,27 ; p<0.001$ ), but the greatest increase compared with controls $(30 \%)$ was apparent at $30 \mathrm{~d}$ after surgery rather than at $10 \mathrm{~d}$. No significant differences in neuronal size were present at $90 \mathrm{~d}$ after the lesion.

The cross-sectional areas of cell nuclei of both OT and VP neurons showed temporal patterns of hypertrophy quite similar to those of their respective neuronal somata (Fig. $4 C, D$ ), but the differences between lesioned and sham-lesioned groups were smaller and generally not statistically significant, with the exception of VP cell nuclei at $30 \mathrm{~d}$ (two-way ANOVA, group-by-day interaction, $F=3.92$; df $=2,27 ; p<0.05)$.

The presence of greater cellular and, to a lesser extent, nuclear hypertrophy of both OT and VP neurons in lesioned animals compared with age-matched sham-lesioned controls supports the hypothesis that sustained increases in metabolic activity occur during collateral sprouting by MNS neurons, especially during the period of most rapid sprouting in the first 4 weeks after the lesion. In addition, maturational increases in the cross-sectional areas of both OT and VP neurons were significant over the $90 \mathrm{~d}$ period of the experiment when the effect of age was tested independently of experimental group (two-way ANOVAs, for $\mathrm{OT}, F=6.97$; df $=2,24 ; p<0.01$; for VP, $F=9.43$; df $=2,27$; $p<0.001)$. Maturational increases in nuclear areas of both OT and VP neurons were also significant between 10 and $90 \mathrm{~d}$ after surgery (two-way ANOVAs, for OT, $F=6.95$; df $=2,24 ; p<$ 0.01 ; for $\mathrm{VP}, F=9.59$; $\mathrm{df}=2,27 ; p<0.001)$. These results are consistent with the increase in the number of axonal profiles observed in the NL during this interval (Fig. 3).

\section{Increases in OT and VP mRNA pools during collateral sprouting}

Changes in the levels of OT and VP mRNA pools are sensitive indicators of alterations in the neurosecretory activity of magnocellular neurons (Dogterom et al., 1977; Balment et al., 1980; Van Tol et al., 1987). We therefore used semiquantitative in situ hybridization to measure the levels of OT and VP mRNAs in the 

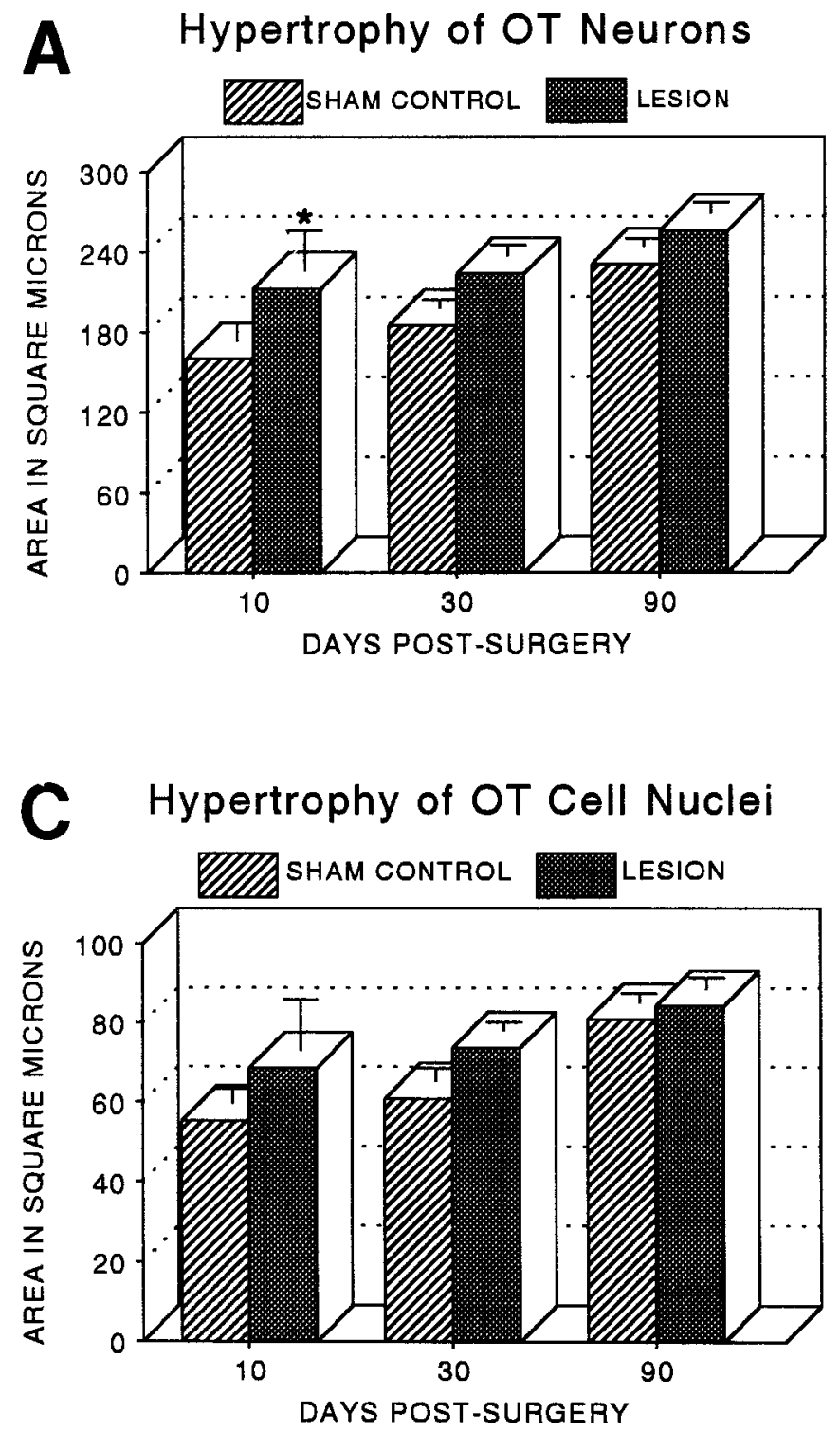

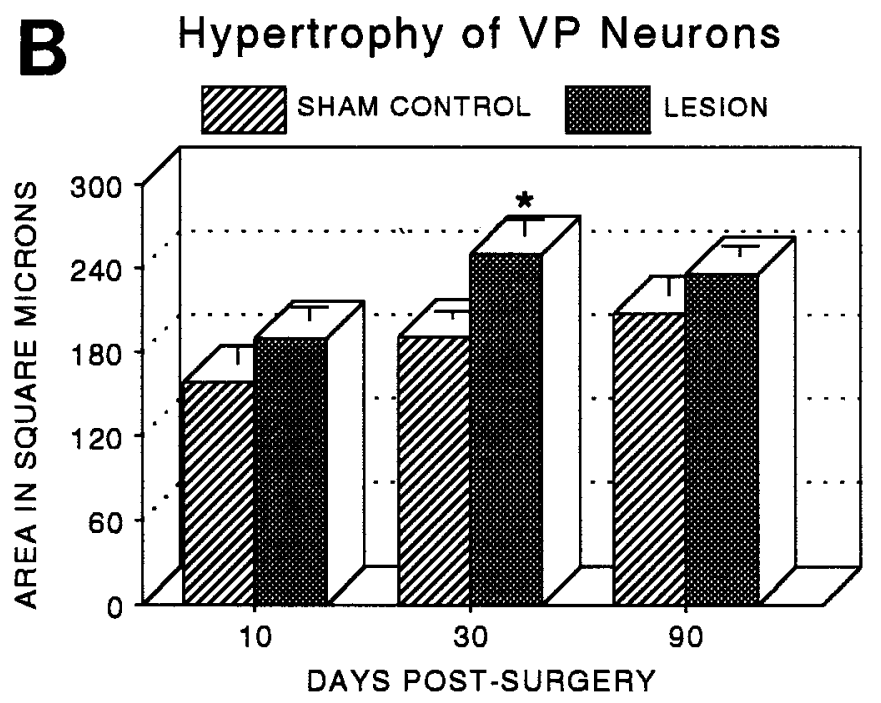

D Hypertrophy of VP Cell Nuclei

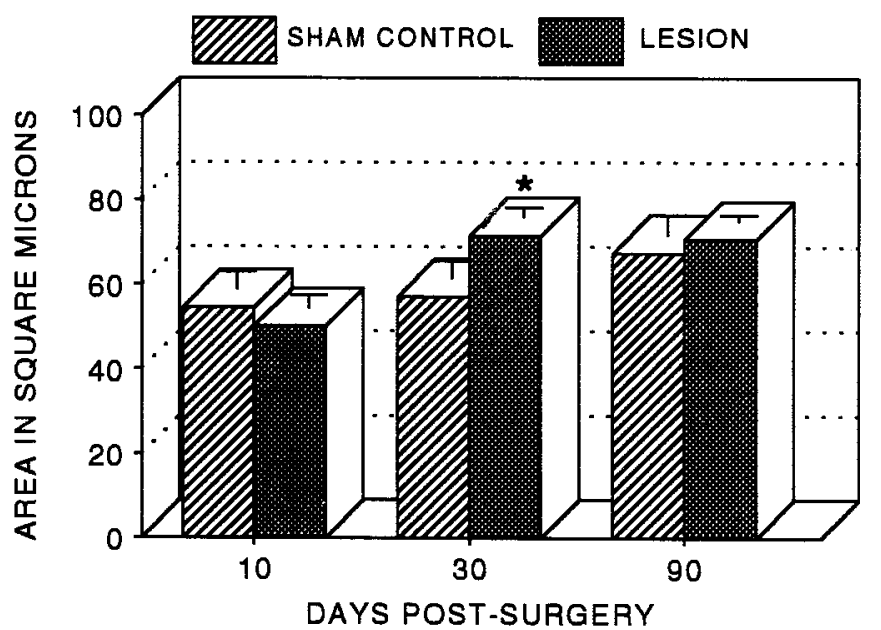

Figure 4. $A, B$, The size of both OT $(A)$ and VP $(B)$ neuronal somata was significantly increased after the hypothalamic lesion (two-way ANOVAs, see Results), with the greatest hypertrophy relative to that of sham controls present during the period of most rapid axonal sprouting $\left({ }^{*} p<0.03\right.$ at $10 \mathrm{~d}$ after the lesion for OT neurons; ${ }^{*} p<0.01$ at $30 \mathrm{~d}$ after the lesion for VP neurons). $C, D$, Hypertrophy of OT $(C)$ and VP $(D)$ cell nuclei followed a similar but less marked pattern, with a significant group difference present only at $30 \mathrm{~d}$ for VP neurons $\left({ }^{*} p<0.05\right)$. Significant maturational increases in both cellular and nuclear size were also observed in OT and VP cells (see Results). Neuronal somata and cell nuclei were measured in the SON contralateral to the hypothalamic lesion or sham lesion. VP and OT cells were identified immunocytochemically on paraffin sections, and only neurons possessing a distinct cell boundary, nuclear envelope, and nucleolus were measured (see Materials and Methods). Fifty somata and their respective nuclei were measured in every subject, and each point and error bar represent the mean and SEM of four to eight animals per group.

SON to determine whether chronic changes in neuronal activity were correlated with the collateral-sprouting response. Analyses were performed at 1 and 4 weeks after surgery because the great majority of the sprouting response occurred during this interval. Measurements were confined to the sprouting SON for the reasons discussed above.

Emulsion autoradiographs of ${ }^{35} \mathrm{~S}$-labeled cRNA probes specific for either VP or OT exon C showed greater hybridization intensity over magnocellular neurons within the contralateral SON at both 1 and 4 weeks after surgery in lesioned rats compared with intact or sham-lesioned age-matched controls (Figs. 5A, B, 6A, B). Computerized densitometric analysis of autoradiographs confirmed that VP and OT mRNA levels were substantially increased during the sprouting response (Fig. 7). Increases in VP mRNA levels were greatest at 1 week after the lesion (one-way ANOVA, $F=39.89 ; \mathrm{df}=4,27 ; p<0.0001$ ), whereas increases in OT mRNA levels were greatest at 4 weeks after the lesion (one-way ANOVA, $F=9.06$; df $=4,28 ; p<0.0001$; see Fig. 7 for comparisons between individual groups). Smaller increases also occurred in the OT and VP mRNA pool levels of the shamlesioned group at 1 week after surgery, but these were not sustained at 4 weeks because both OT and VP mRNA levels returned to values identical to those of intact animals.

These results are consistent with the hypothesis that both OT and VP neurons exhibit chronic increases in neuronal activity during the period when they are undergoing the most rapid 

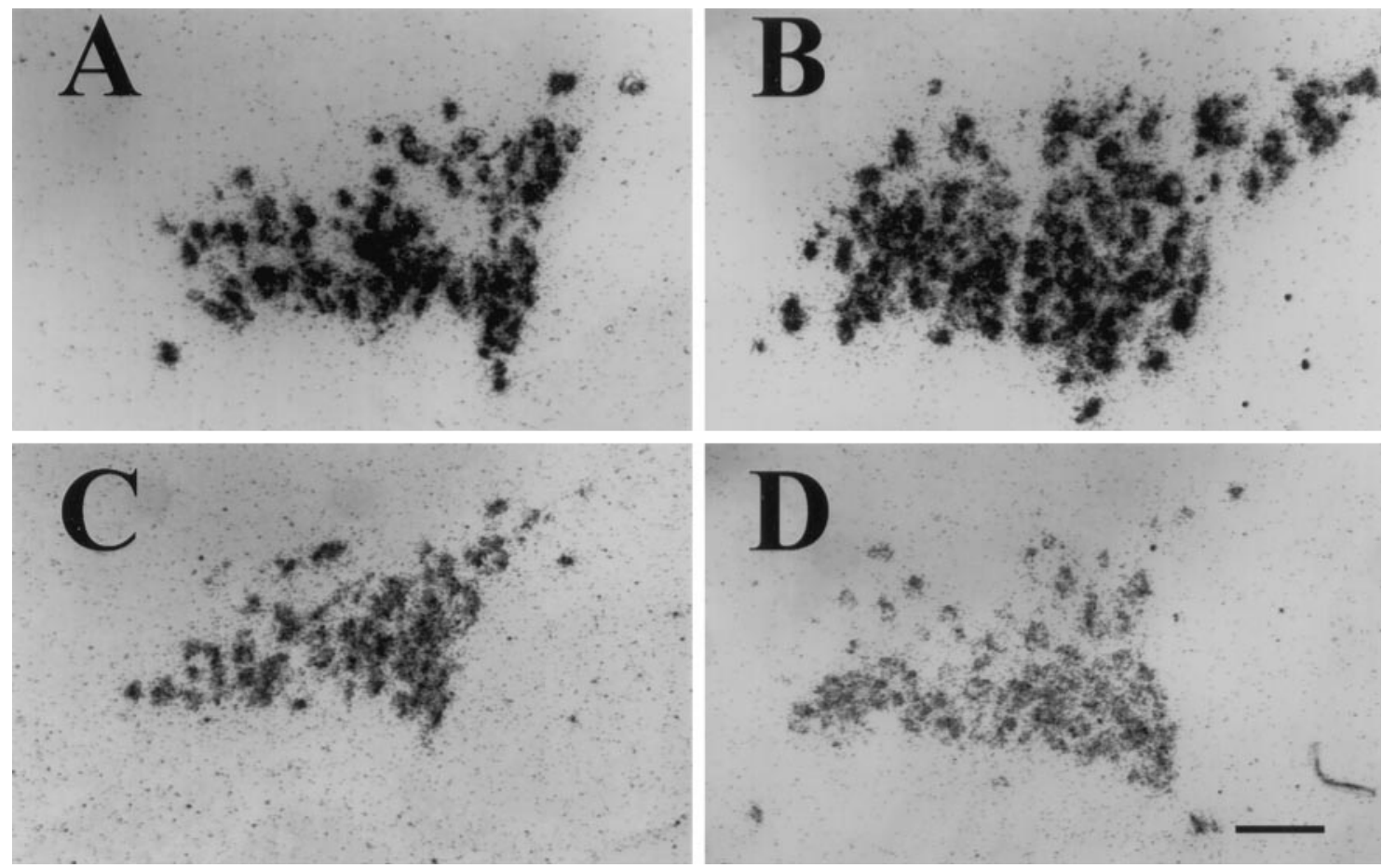

Figure 5. In situ hybridization revealed that VP mRNA levels were increased during the sprouting response in magnocellular neurons of the SON contralateral to the hypothalamic lesion and that this increase was blocked by $\mathrm{CH}$. Shown are emulsion autoradiographs of the SON at 1 week after surgery when the group differences in VP mRNA levels were greatest. $A$, Sham-lesioned control. $B$, Lesion. $C$, Sham-lesioned control with CH. $D$, Lesion with $\mathrm{CH}$. Sections were incubated with ${ }^{35} \mathrm{~S}$-labeled cRNA probes specific for VP exon C (see Materials and Methods). Scale bar, $100 \mu \mathrm{m}$.

collateral sprouting. The smaller and more transient increase in mRNA levels seen in sham-lesioned animals suggests that although surgical stress (including dehydration and blood loss) activates OT and VP neurons, this effect is not sufficient by itself to account for the greater and more sustained activation that occurs during the sprouting response.

\section{Increased COX activity in the NL during collateral sprouting}

COX activity in axonal terminals has been shown to reflect changes in neuronal firing rate in a variety of situations (Erecinska and Silver, 1989; Wong-Riley, 1989; Hevner and Wong-Riley, 1990). We therefore used a histochemical assay to determine whether changes in COX activity in the NL were correlated with collateral sprouting of MNS axons. An increase in the intensity of the COX reaction in sections of the NL was apparent at 4 weeks after the lesion compared with intact controls (Fig. 8A,B), and quantitative densitometry (Fig. 9) confirmed that both treatment group and postsurgical interval had significant effects on $\mathrm{COX}$ activity in the NL (two-way ANOVA, group effect, $F=3.78$; df $=$ $4,56 ; p<0.01$; time effect, $F=6.26$; df $=1,56 ; p<0.02)$. The highest activity was present during the sprouting response at 4 weeks after the lesion (see Fig. 9 for comparisons between individual groups). No change in activity was seen at either 1 or 4 weeks in sham-lesioned controls.

These results indicate that an increase in oxidative metabolism indicative of increased neurosecretory activity was present in the sprouting NL at 4 weeks after the lesion when the number of axons was approaching that of intact animals. Although no increase in COX activity occurred at 1 week after the lesion in sprouting animals, no significant decrease was apparent in spite of the degeneration of one-half of the neurosecretory terminals. The absence of a decline in COX levels at this time suggests that activity in the undamaged axons was already increased early in the sprouting response.

\section{Effectiveness of $\mathrm{CH}$ in reducing neuronal activity in the MNS}

Chronic treatment with desmopressin in combination with a liquid diet (Verbalis and Drutarosky, 1988) was effective in lowering mean plasma sodium and plasma osmolality $\sim 25 \%$ throughout the entire 4 week experimental period (Fig. 10). No changes in either measure were observed at any time in intact, lesioned, or sham-lesioned groups maintained on a standard lab chow diet with water available ad libitum.

Induction of $\mathrm{CH}$ in turn prevented the increase in neuronal activity that was apparent in the MNS of untreated (normonatremic) rats after the hypothalamic lesion. Emulsion autoradiography after in situ hybridization of either OT or VP mRNA revealed a decrease in signal intensity in the SON of both lesioned and sham-lesioned groups in hyponatremic compared with normonatremic animals (Figs. 5, 6). Quantification of relative mRNA levels by computerized densitometry showed that the increases in both VP and OT mRNA pools observed after the lesion in normonatremic animals were completely abolished by $\mathrm{CH}$ (Fig. 7). In addition, VP mRNA pools in lesioned and sham-lesioned hyponatremic groups were reduced to levels significantly below those of intact normonatremic animals at both 1 and 4 weeks (1 week data, one-way ANOVA, $F=39.89$; df $=4,27$; $p<0.0001$; 4 week data, one-way ANOVA, $F=7.29$; df $=4$, 26; $p<0.001$; see Fig. 7 for comparisons between individual groups). Although a similar trend was apparent in OT mRNA levels, the differences between lesioned or sham-lesioned hyponatremic groups and intact normonatremic animals were not statistically significant. 

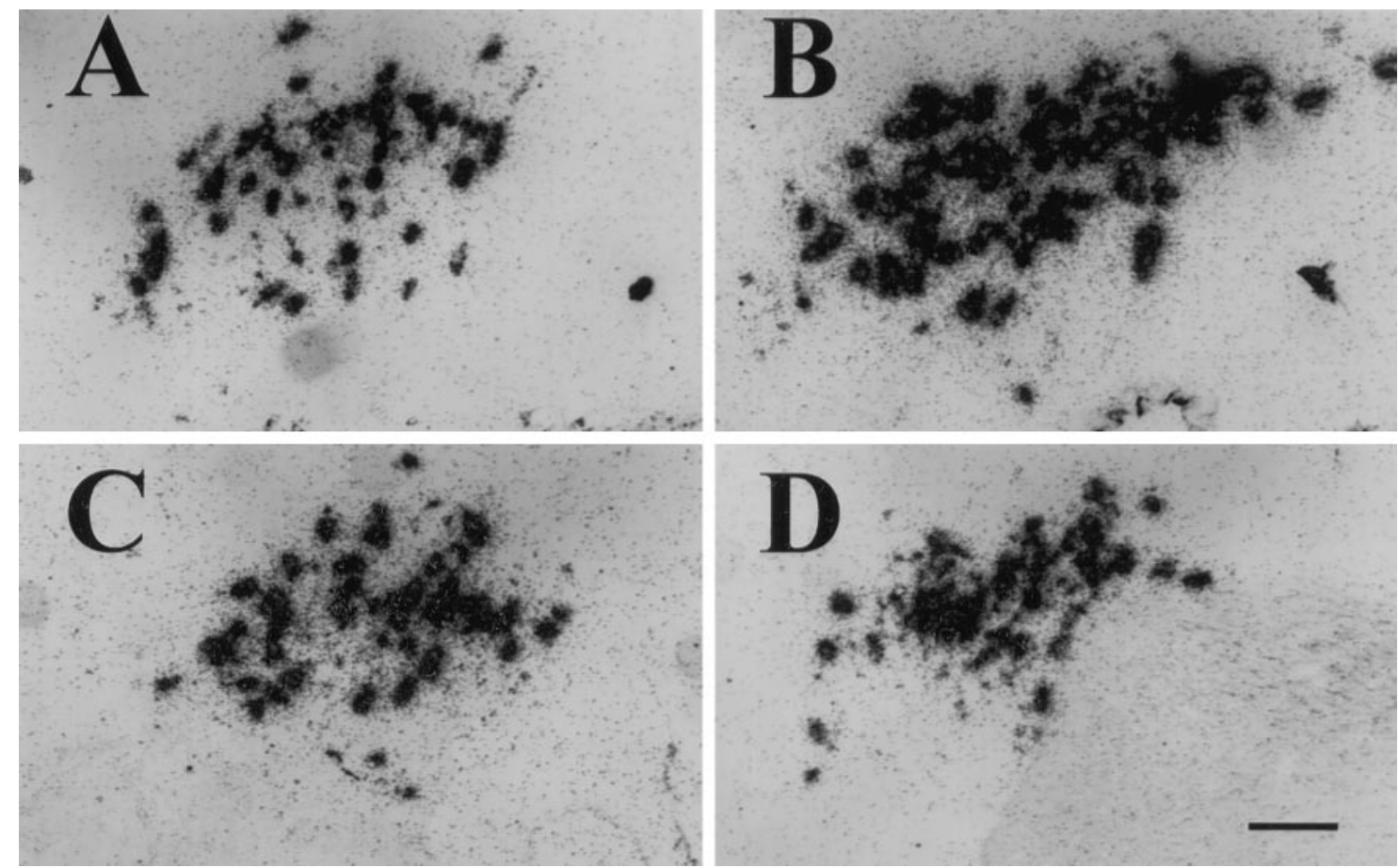

Figure 6. In situ hybridization revealed that OT mRNA levels were increased during the sprouting response in magnocellular neurons of the SON contralateral to the hypothalamic lesion and that this increase was blocked by $\mathrm{CH}$. Shown are emulsion autoradiographs of the SON at 4 weeks after surgery when the group differences in OT mRNA levels were greatest. $A$, Sham-lesioned control. $B$, Lesion. $C$, Sham-lesioned control with $C H$. $D$, Lesion with $\mathrm{CH}$. Sections were incubated with ${ }^{35}$ S-labeled cRNA probes specific for OT exon C (see Materials and Methods). Scale bar, $100 \mu \mathrm{m}$.

VP MRNA LEVELS IN THE SON

OT MRNA LEVELS IN THE SON
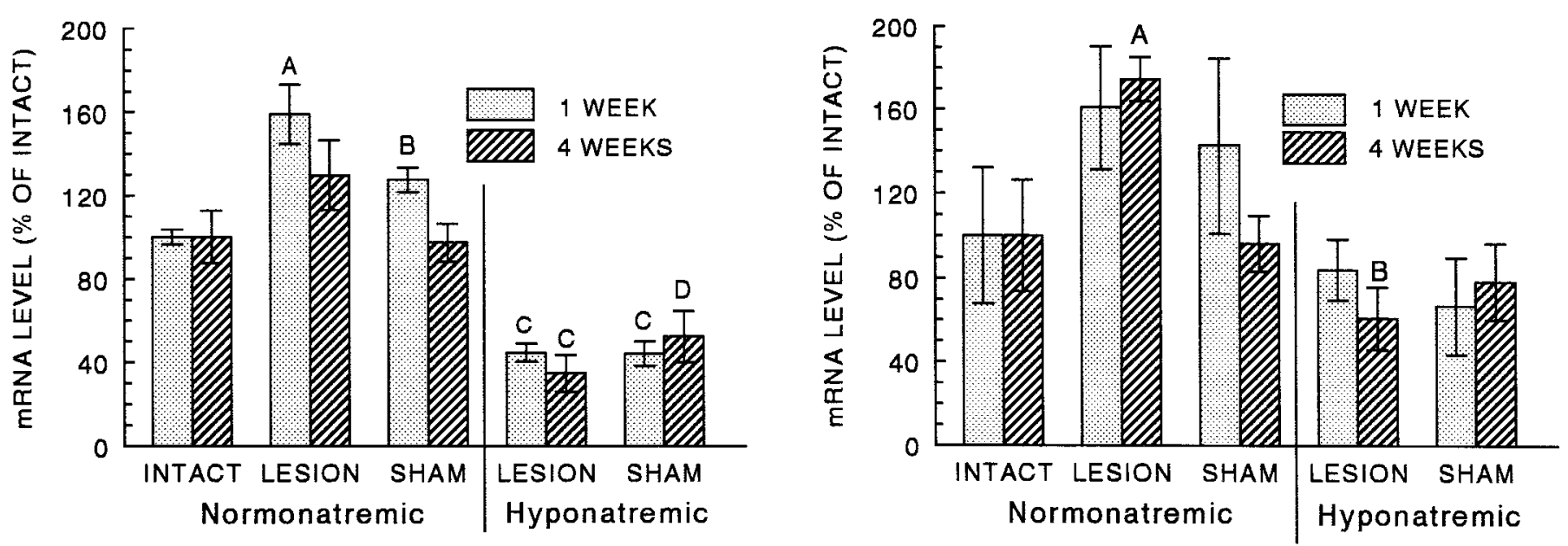

Figure 7. Semiquantitative densitometric analysis of emulsion autoradiographs after in situ hybridization showed that VP (left) and OT (right) mRNA levels were elevated in the contralateral (sprouting) SON after the hypothalamic lesion in normonatremic rats. Left, VP mRNA was greatest at 1 week after the lesion, and $\mathrm{CH}$ blocked this increase and caused mRNA levels to fall below those of intact controls at both 1 and 4 weeks $(A$, greater than intact or sham, $p<0.01 ; B$, greater than intact, $p<0.02$; $C$, less than all normonatremic groups, $p<0.02 ; D$, less than normonatremic lesion, $p<0.001$ ). Right, OT mRNA was greatest at 4 weeks after the lesion, and $\mathrm{CH}$ blocked this increase $(A$, greater than intact or sham, $p<0.01 ; B$, less than normonatremic lesion, $p<0.0001$ ). In situ hybridization was performed using ${ }^{35} \mathrm{~S}$-labeled cRNA probes specific for VP or OT exon C (see Materials and Methods). Levels are expressed as the percent of the age-matched intact control value, and each point and error bar represent the mean and SEM of four to nine animals.

$\mathrm{CH}$ was also effective in reducing COX activity in the NL of lesioned rats to levels barely above background (Fig. 8C). Quantification of this reduction by computerized densitometry confirmed that the increase in COX activity seen in the NL of animals undergoing axonal sprouting at 4 weeks after the lesion was com- pletely abolished by hyponatremia (Fig. 9). A similar decrease was not seen in sham-lesioned controls, suggesting that COX activity in newly formed or growing axon terminals was more sensitive to the hyponatremia-induced reduction in neurosecretory activity than was COX activity within more mature terminals. 

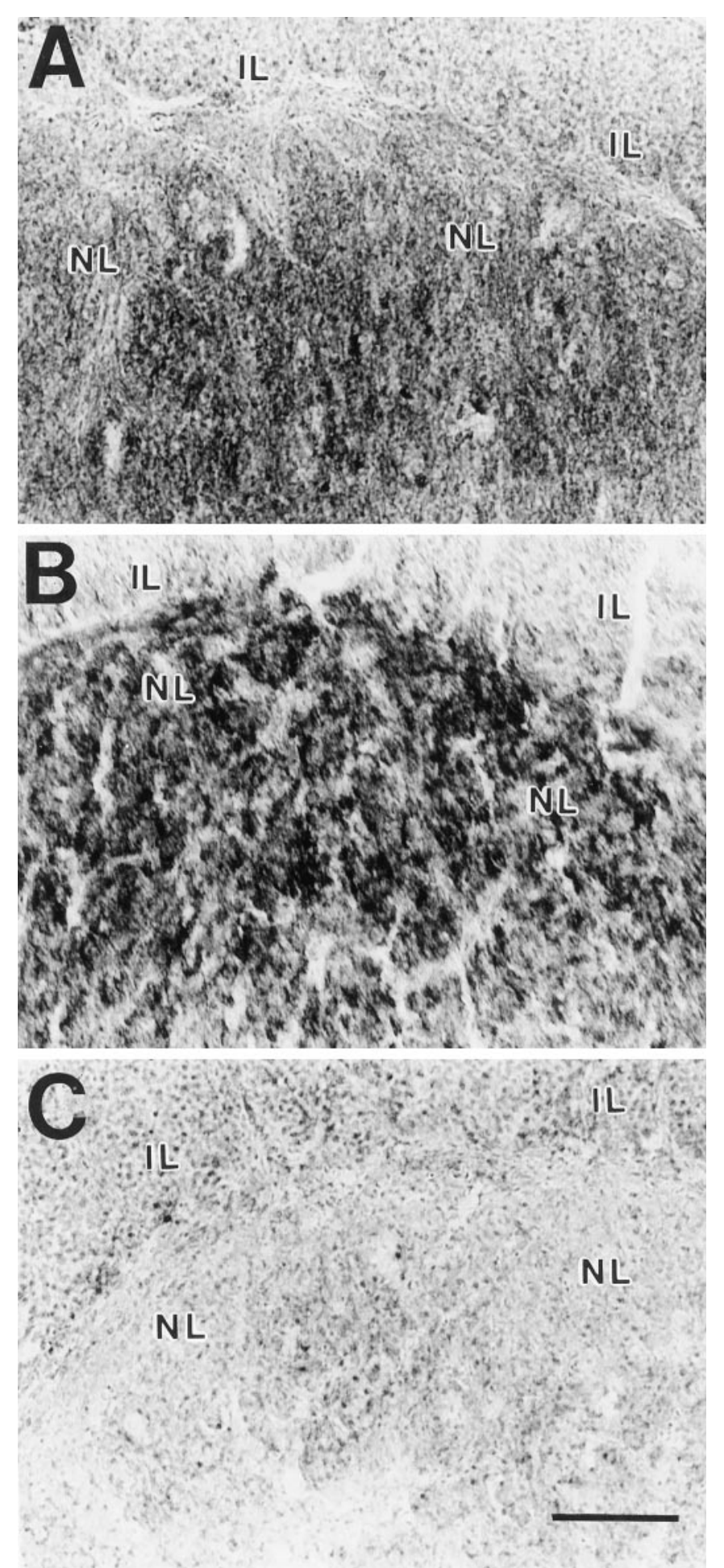

Figure 8. Histochemical detection of COX activity in the NL. Sections from intact control $(A), 4$ week postlesion $(B)$, and $\mathrm{CH} 4$ week postlesion $(C)$ animals are shown. Note the increased density of the reaction product in $B$ after collateral sprouting of magnocellular axons in the NL and the reduction of COX activity to near the background level in the hyponatremic animal $(C)$ in which sprouting is inhibited. $I L$, Intermediate lobe. Scale bar, $100 \mu \mathrm{m}$.

\section{COX ACTIVITY IN THE NL}

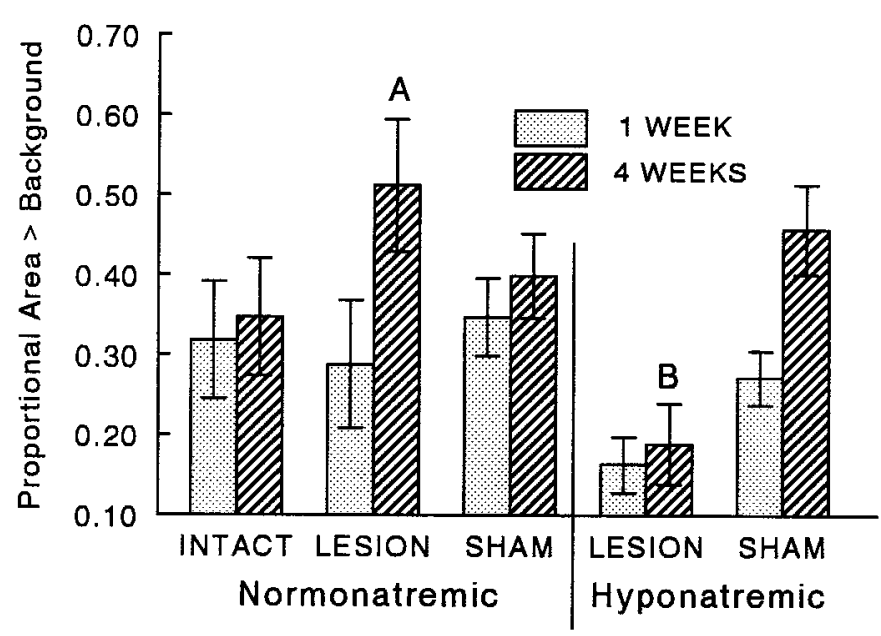

Figure 9. Quantitative densitometry showed that COX activity in magnocellular terminals was significantly increased during the sprouting response in lesioned animals at 4 weeks $(A$, greater than 1 week intact or lesion, $p<0.02$; marginally greater than 4 week intact, $p<0.07)$. In contrast, induction of $\mathrm{CH}$ abolished the lesion-induced increase in activity $(B$, less than 4 week lesion, $p<0.001$ ) but had no effect in sham-lesioned controls. The proportional area of the NL with signal intensity above background was determined densitometrically after histochemical detection of COX activity in the neurosecretory terminal field (see Materials and Methods). Each point and error bar represent the mean and SEM of six to eight animals.

Taken together, these data indicate that induction of $\mathrm{CH}$ was effective in preventing the increase in neuronal activity associated with the postlesion collateral-sprouting response of MNS neurons.

\section{Inhibition of collateral sprouting by $\mathbf{C H}$}

Induction of $\mathrm{CH}$ at $32 \mathrm{~d}$ of age had no effect on the total number of axons in the NL of intact rats killed 10 or $31 \mathrm{~d}$ later (Fig. 11). The decline in total axon numbers 1 week after a unilateral hypothalamic lesion (made $3 \mathrm{~d}$ after induction of hyponatremia) was also similar to that seen in normonatremic animals (Fig. 3). However, in marked contrast to the recovery of axon numbers seen at 4 weeks after the lesion in normonatremic rats (Fig. 3), there was no change in the number of axons between 1 and 4 weeks after the lesion in hyponatremic animals (Fig. 11). Thus $\mathrm{CH}$ completely blocked the robust axonal sprouting response of uninjured contralateral MNS neurons that occurred in normonatremic rats. This result is consistent with the hypothesis that increased neuronal activity is required for collateral sprouting to occur.

The initial decline in the number of axons seen at 1 week in normonatremic sham-lesioned animals (Fig. 3) was also apparent in hyponatremic sham-lesioned controls (Fig. 11), as was the subsequent increase at 4 weeks. However, although the magnitude of these changes was somewhat greater in the hyponatremic animals, they remained statistically nonsignificant.

\section{DISCUSSION}

\section{Increased neuronal activity in sprouting neurons}

The present results confirm and extend our earlier description of the collateral-sprouting response of intact magnocellular neurons after unilateral destruction of the hypothalamo-neurohypophysial 

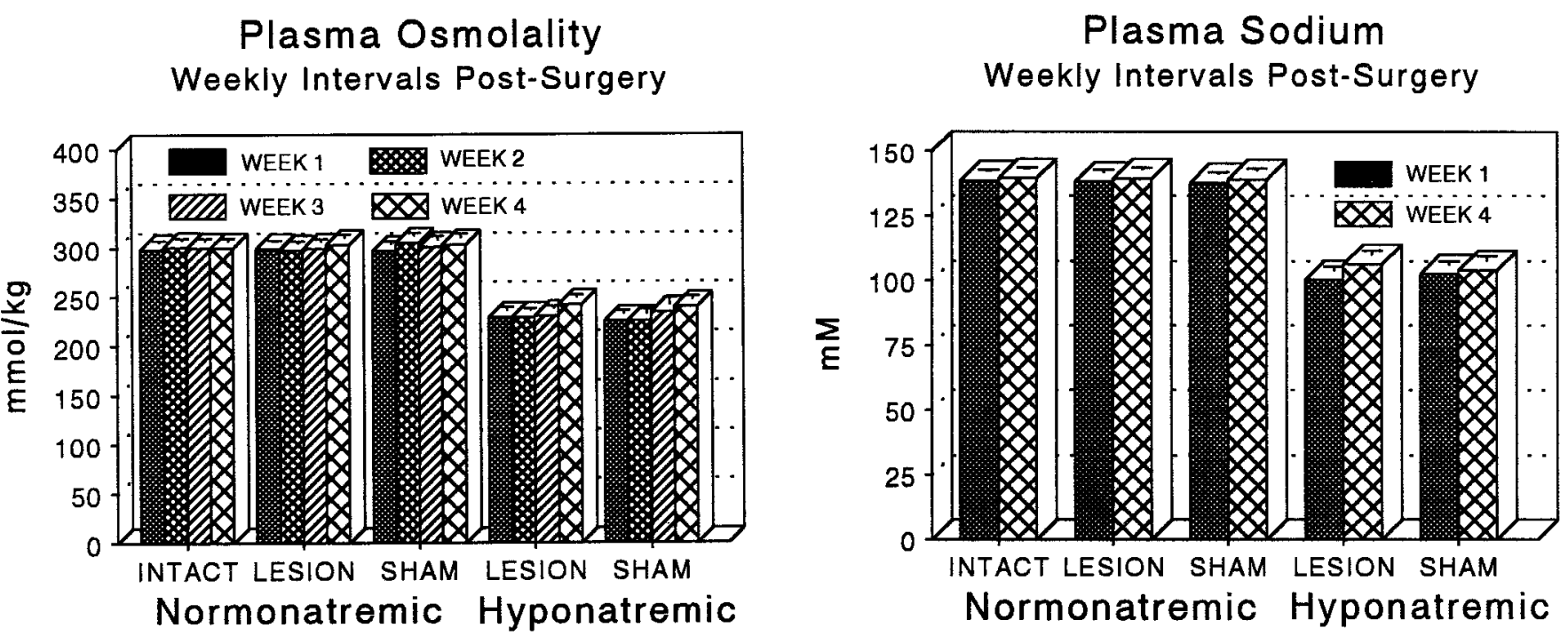

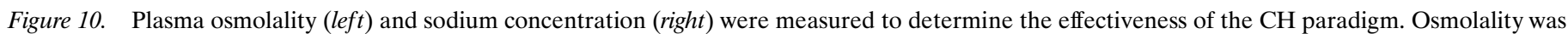

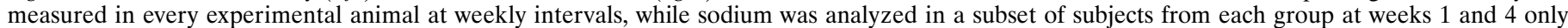

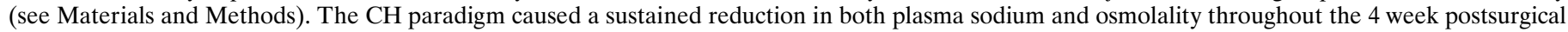

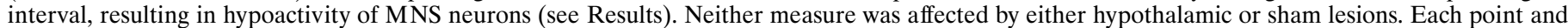
error bar represent the mean and SEM of 6-17 animals (for osmolality) or 4-8 animals (for sodium).

\section{Inhibition of Collateral Sprouting in the NL by Chronic Hyponatremia}

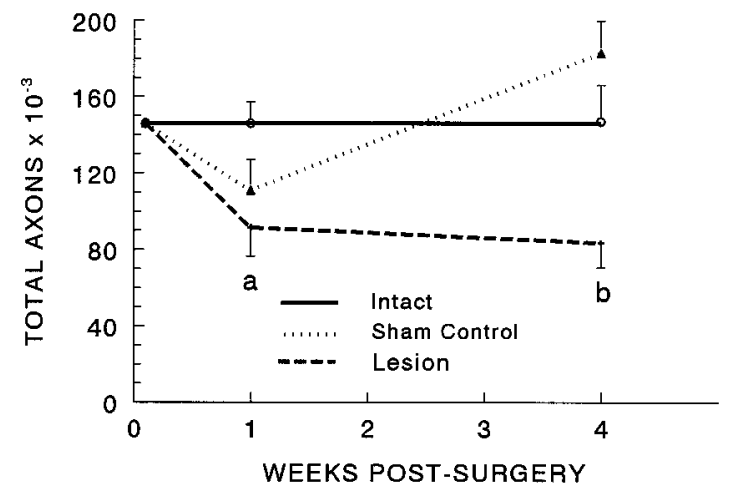

Figure 11. Determination of the total number of axonal profiles in the $\mathrm{NL}$ revealed that collateral sprouting did not occur when $\mathrm{CH}$ was induced starting $3 \mathrm{~d}$ before the hypothalamic lesion and maintained throughout the 4 week postsurgical period. Axon numbers were significantly reduced at 1 week in lesioned animals and remained lower than intact or sham control values at 4 weeks (two $\times$ three ANOVA, group effect, $F=9.65$; $\mathrm{df}=2,28 ; p<0.001 ;$ post hoc comparisons, $a$, lesion less than intact, $p<$ 0.05 ; $b$, lesion less than intact or sham, $p<0.005)$. $\mathrm{CH}$ had no significant effect on the number of axons in intact or sham-lesioned animals. Data were collected as described for Figure 3, and each data point and error bar represent the mean and SEM of five to seven animals. No data were collected at the time 0 point, which is set equal to the 1 week intact control value simply to illustrate the effect of surgery on each experimental group.

tract (Watt and Paden, 1991). Sprouting in the MNS is remarkable both for the robustness of the initial response, which returns the total number of axons to normal levels by doubling their number between 1 and 4 weeks after the lesion, and for the slower but prolonged increase in the number of axons apparent in all groups between 4 and 13 weeks after surgery. This period corresponds to 63-125 d of age, indicating that growth of axons within the NL of the rat continues for considerably longer than has been thought (Galabov and Schiebler, 1978; Krisch, 1980).
The presence of neuronal and nuclear hypertrophy, elevated neuropeptide mRNA pools, and increased COX activity in neurosecretory terminals all support the conclusion that magnocellular neurons are hyperactive during the period of most rapid collateral sprouting between 1 and 4 weeks after the hypothalamic lesion. The sizes of both OT and VP mRNA pools are known to be sensitive to acute as well as chronic increases in secretion of the peptides (Dogterom et al., 1977; Balment et al., 1980; Van Tol et al., 1987). Therefore, the findings that VP and OT mRNA pools are elevated in the sprouting SON at both 1 and 4 weeks after the lesion, together with our previous observations of a persistent increase in urine osmolality accompanied by decreased urine volume and water intake beginning $3 \mathrm{~d}$ after the lesion (Watt and Paden, 1991), are strongly indicative of a sustained increase in neurosecretory activity that both precedes and accompanies the sprouting response. Although increased COX activity was not seen in the NL until 4 weeks, delays as long as 4-6 weeks between increases in neuronal activity and increased COX staining in axon terminals are typical (Wong-Riley et al., 1981; Wong-Riley and Riley, 1983) because COX staining reflects enzyme number within mitochondria (Hevner and Wong-Riley, 1990, 1993). Thus the fact that a significant increase in COX staining is first apparent in the NL of sprouting animals at 4 weeks is not inconsistent with the conclusion that increased impulse activity begins soon after the lesion. Taken together, we believe these data represent the first direct demonstration of a sustained increase in the activity of identified CNS neurons undergoing axonal sprouting.

The appearance of cellular and nuclear hypertrophy is also indicative of increased metabolic activity in sprouting OT and VP neurons (Peterson, 1966; Morris and Dyball, 1974). Cellular hypertrophy has also been correlated with collateral sprouting by intact neurons in other regions of the CNS (Goldschmidt and Steward, 1980; Hendrickson and Dineen, 1982; Headon et al., 1985; Pearson et al., 1987). Hypertrophy probably reflects increased metabolic rate associated with both axonal growth and increased impulse activity. However, the return of both the cel- 
lular and nuclear size of sprouting OT and VP neurons to near control values at $90 \mathrm{~d}$ indicates that it is not simply maintenance of a larger axonal arbor that results in hypertrophy. These cells must support substantially enlarged arbors because the total number of axons in the NL at this time is equal to that of intact animals possessing a full complement of magnocellular neurons.

\section{Inhibition of neuronal activity and sprouting by $\mathbf{C H}$}

$\mathrm{CH}$ completely blocked the increases in OT and VP mRNA levels and COX activity induced by the hypothalamic lesion in normonatremic rats, indicating that $\mathrm{CH}$ was effective in preventing lesioninduced hyperactivity of magnocellular neurons. At the same time, collateral sprouting was completely abolished in hyponatremic rats. Because OT and VP are both natriuretic hormones and are released in response to osmotic stimulation in the rat (Landgraf et al., 1988; Windle et al., 1995), the reduction in plasma sodium during $\mathrm{CH}$ inhibits both cell types, and $\mathrm{CH}$ also suppresses excitatory inputs from osmoreceptive neurons in the anterior hypothalamus (Verbalis, 1993). Thus the present results provide strong support for the conclusion that axonal sprouting in the MNS is dependent on ongoing synaptic excitation of magnocellular neurons. However, because $\mathrm{CH}$ was maintained for 4 weeks, these results do not distinguish between effects of reduced neuronal activity on the initiation versus the maintenance of the sprouting response, an issue that must be addressed in future experiments.

The ability of $\mathrm{CH}$ to block lesion-induced changes in parvocellular neurosecretory axons within the median eminence has also been investigated (Dohanics et al., 1994). Bilateral lesions of the PVN eliminate all VP staining in the zona externa, but OT immunoreactivity becomes detectable after 6 weeks. This effect, interpreted as sprouting of OT axons, is blocked by $\mathrm{CH}$. Although these studies are subject to potential artifacts because of alterations in the peptide content and immunoreactivity of OT and $\mathrm{VP}$ axons, they are consistent with the present findings.

\section{Potential causes of increased activity in sprouting MNS neurons}

There are several potential explanations for the increased activity observed in OT and VP neurons during the sprouting response. One possibility is that signals arising from the anterograde degeneration of severed neurosecretory axons in the NL are required to stimulate collateral sprouting by uninjured magnocellular neurons. Concomitant increases in activity might then represent an intrinsic aspect of the neuronal response to partial denervation of the terminal field. One likely source of such signals is glial and/or endothelia cells, and we have observed that axonal degeneration in the NL leads to rapid activation of phagocytic microglia (Moffett and Paden, 1994). Activated microglia can produce a variety of cytokines and other growth factors (Giulian et al., 1986; Nakajima and Kohsaka, 1993; Guthrie et al., 1995) and have been postulated to play an early role in stimulating collateral sprouting after deafferentation of other brain regions such as the hippocampus (Jensen et al., 1994; Schoen and Kreutzberg, 1994; Guthrie et al., 1995; Breese et al., 1996). Vascular endothelia are another potential source of growth factors acting on neurosecretory axons (Raisman, 1973; Bach and Bondy, 1992). It remains to be determined whether endothelia, microglia, and/or pituicytes, the resident astrocytes of the NL (Salm et al., 1982), play an essential role in stimulating collateral sprouting in the MNS.

An alternative possibility is that sustained increases in neuro- nal activity resulting from secondary damage to hypothalamic circuitry may have caused sprouting to occur independently of axonal degeneration. Our unilateral lesion probably disrupted connections between the various nuclei of the MNS (Nilaver et al., 1980; Takano et al., 1990; Thellier et al., 1994) that may function to coordinate their activity (Summy-Long et al., 1994; Neumann et al., 1995). If so, the lesion may have caused disinhibition of contralateral magnocellular neurons. The subsequent increase in VP and OT secretion would act to decrease urine volume and increase urine osmolality, and animals would drink less to maintain fluid balance. Alternatively, the lesion may have disrupted afferent and efferent connections of areas involved in control of drinking such as the lateral hypothalamus (Gray and Everitt, 1970) or zona incerta (Evered and Mogenson, 1976), thereby inducing hypodipsia directly. Secretion of VP and OT by uninjured magnocellular neurons would then increase to maintain osmotic homeostasis.

In either of these scenarios, one is led to the conclusion that collateral sprouting by intact magnocellular neurons may occur as a direct response to increased activity rather than as a consequence of axonal loss in the NL. This possibility is supported by studies demonstrating that the survival of OT and VP neurons after axotomy is dependent on continued neuronal activity (Herman et al., 1987; Dohanics et al., 1996) and by indirect evidence of increased axonal growth in the NL of intact animals after osmotic stimulation (Mander and Morris, 1994). The hypothesis that increased neuronal activity may be sufficient in itself to induce axonal sprouting in the MNS should therefore be tested in future experiments.

\section{Neuronal activity versus degeneration as stimulants of collateral sprouting}

Determining the relative importance of increased spike activity versus neuronal degeneration in stimulating collateral sprouting is an issue of general significance. Our findings suggest that the most robust collateral sprouting may occur when deafferentation of terminal zones and increased activity coincide, and studies of collateral sprouting by parvocellular neuroendocrine cells support this conclusion. The axons of parvocellular VP neurons from one PVN apparently expand their terminal field across the midline within the zona externa of the median eminence after destruction of the contralateral PVN, but only if neurosecretory activity is stimulated by adrenalectomy (Silverman and Zimmerman, 1982).

Increased activity alone appears to be sufficient to induce collateral sprouting in some cases. For example, widespread increases in limbic-hippocampal activity induced by kindling stimulation or by spontaneous seizures can induce sprouting of mossy fiber collaterals in the dentate gyrus in the absence of detectable cell death (Sutula et al., 1988; Cavazos et al., 1991; Noebels et al., 1997; Stringer et al., 1997). However, kainate-induced seizure activity has been reported to result in more extensive mossy fiber sprouting than has kindling (Stringer et al., 1997), and in this model excitotoxic destruction of CA3, CA4, and dentate hilar neurons occurs within the dentate molecular layer before the onset of sprouting (Represa et al., 1994, 1995). Thus seizure activity and degenerative events may act synergistically to stimulate sprouting of mossy fiber collaterals.

One key to understanding the interaction between increased activity and degenerative changes in stimulating collateral sprouting is to determine the responses of various growth factors to these events. For example, activity-induced changes in mRNA 
expression for a variety of growth factors have been documented within neurons in the hippocampus (Neeper et al., 1995; Thoenen, 1995; Gall et al., 1997), whereas degeneration of axon terminals after partial deafferentation is associated with increased expression of growth factors by hippocampal glial cells (Guthrie et al., 1995, 1997; Fagan et al., 1997). Synergism between multiple growth factors might therefore mediate interactions between altered neuronal activity and degenerative events to affect the extent of collateral sprouting by different neuronal populations in a situation-specific manner.

Although the specific growth factors that may stimulate axonal sprouting by magnocellular neurons are yet to be identified, components of several growth factor systems have been localized within the MNS. These include IGF-I immunoreactivity (Aguado et al., 1992) and mRNA for its high-affinity receptor (Aguado et al., 1993) within the SON and both immunoreactivity and mRNA for IGF-binding proteins within the NL (Bach and Bondy, 1992; Zhou et al., 1997). High levels of basic FGF are found within the NL (Gonzalez et al., 1994), and mRNA for BDNF is present within PVN neurons where it is upregulated during osmotic stimulation (Castren et al., 1995). The CNTF receptor $\alpha$ is expressed by MNS neurons (MacLennan et al., 1996; Lee et al., 1997), and CNTF has been shown to exert neurotrophic effects on VP neurons in vitro (Vutskits et al., 1998). Because of the present demonstration that lesion-induced collateral sprouting by MNS neurons is activity dependent, future studies may use this system to determine whether particular growth factors are involved in linking either terminal degeneration or increased neuronal activity to the sprouting response.

\section{REFERENCES}

Adams JC (1981) Heavy metal intensification of DAB-based HRP reaction product. J Histochem Cytochem 29:775-784.

Aguado F, Fernández T, Martínez-Murillo R, Rodrigo J, Cacicedo L, Sánchez-Franco F (1992) Immunocytochemical localization of insulin-like growth factor I in the hypothalamo-hypophyseal system of the adult rat. Neuroendocrinology 56:856-863.

Aguado F, Rodrigo J, Cacicedo L, Mellstrom B (1993) Distribution of insulin-like growth factor-I receptor mRNA in rat brain. Regulation in the hypothalamo-neurohypophysial system. J Mol Endocrinol 11:231-239.

Bach MA, Bondy CA (1992) Anatomy of the pituitary insulin-like growth factor system. Endocrinology 131:2588-2594.

Balment RJ, Brimble MJ, Forsling ML (1980) Release of oxytocin induced by salt loading and its influence on renal excretion in the male rat. J Physiol (Lond) 308:439-445.

Ben-Ari Y (1995) Activity-dependent forms of plasticity. J Neurobiol 26:295-298.

Breese CR, D'Costa A, Rollins YD, Adams C, Booze RM, Sonntag WE, Leonard S (1996) Expression of insulin-like growth factor-1 (IGF-1) and IGF-binding protein 2 (IGF-BP2) in the hippocampus following cytotoxic lesion of the dentate gyrus. J Comp Neurol 369:388-404.

Castren E, Thoenen H, Lindholm D (1995) Brain-derived neurotrophic factor messenger RNA is expressed in the septum, hypothalamus and in adrenergic brain stem nuclei of adult rat brain and is increased by osmotic stimulation in the paraventricular nucleus. Neuroscience 64:71-80.

Cavazos JE, Golarai G, Sutula TP (1991) Mossy fiber synaptic reorganization induced by kindling: time course of development, progression, and permanence. J Neurosci 11:2795-2803.

Chen C, Tonegawa S (1997) Molecular genetic analysis of synaptic plasticity, activity-dependent neural development, learning, and memory in the mammalian brain. Annu Rev Neurosci 20:157-184.

Diamond J, Holmes M, Coughlin M (1992) Endogenous NGF and nerve impulses regulate the collateral sprouting of sensory axons in the skin of the adult rat. J Neurosci 12:1454-1466.

Dogterom J, Van Wimersma Greidanus TjB, Swaab DF (1977) Evidence for the release of vasopressin and oxytocin into cerebrospinal fluid: measurements in plasma and CSF of intact and hypophysectomized rats. Neuroendocrinology 24:108-117.

Dohanics J, Hoffman GE, Verbalis JG (1994) Hyponatremia inhibits sprouting of oxytocinergic axons following bilateral lesions of the paraventricular nucleus in rats. Neurosci Lett 165:51-54.

Dohanics J, Hoffman GE, Verbalis JG (1996) Chronic hyponatremia reduces survival of magnocellular vasopressin and oxytocin neurons after axonal injury. J Neurosci 16:2373-2380.

Dudek FE, Spitz M (1997) Hypothetical mechanisms for the cellular and neurophysiologic basis of secondary epileptogenesis: proposed role of synaptic reorganization. J Clin Neurophysiol 14:90-101.

Erecinska M, Silver IA (1989) ATP and brain function. J Cereb Blood Flow Metab 9:2-19.

Evered MD, Mogenson GJ (1976) Regulatory and secondary water intake in rats with lesions of the zona incerta. Am J Physiol 230:1049-1057.

Fagan AM, Suhr ST, Lucidi-Phillipi CA, Peterson DA, Holtzman DM, Gage FH (1997) Endogenous FGF-2 is important for cholinergic sprouting in the denervated hippocampus. J Neurosci 17:2499-2511.

Galabov P, Schiebler TH (1978) The ultrastructure of the developing neural lobe. Cell Tissue Res 189:313-329.

Gall CM, Lauterborn JC, Guthrie KM, Stinis CT (1997) Seizures and the regulation of neurotrophic factor expression: associations with structural plasticity in epilepsy. Adv Neurol 72:9-24.

Giulian D, Baker TJ, Shih LN, Lachman LB (1986) Interleukin 1 of the central nervous system is produced by ameboid microglia. J Exp Med 164:594-604.

Goldschmidt RB, Steward O (1980) Time course of increases in retrograde labeling and increases in cell size of entorhinal cortex neurons sprouting in response to unilateral entorhinal lesions. J Comp Neurol 189:359-379.

Gonzalez AM, Logan A, Ying W, Lappi DA, Berry M, Baird A (1994) Fibroblast growth factor in the hypothalamic-pituitary axis: differential expression of fibroblast growth factor-2 and a high affinity receptor. Endocrinology 134:2289-2297.

Gray RH, Everitt AV (1970) Hypophagia and hypodipsia induced by unilateral hypothalamic lesions in the rat. Am J Physiol 219:398-402.

Gundersen HJG (1977) Notes on the estimation of the numerical density of arbitrary profiles: the edge effect. J Microsc 111:219-223.

Guthrie KM, Nguyen T, Gall CM (1995) Insulin-like growth factor-1 mRNA is increased in deafferented hippocampus: spatiotemporal correspondence of a trophic event with axon sprouting. J Comp Neurol 352:147-160.

Guthrie KM, Woods AG, Nguyen T, Gall CM (1997) Astroglial ciliary neurotrophic factor mRNA expression is increased in fields of axonal sprouting in deafferented hippocampus. J Comp Neurol 386:137-148.

Headon MP, Sloper JJ, Hiorns RW, Powell TPS (1985) Effects of monocular closure at different ages on deprived and undeprived cells in the primate lateral geniculate nucleus. Brain Res Dev Brain Res 18:57-78.

Hendrickson A, Dineen JT (1982) Hypertrophy of neurons in dorsal lateral geniculate nucleus following striate cortex lesions in infant monkeys. Neurosci Lett 30:217-222.

Herman JP, Marciano FF, Wiegand SJ, Gash DM (1987) Selective cell death of magnocellular vasopressin neurons in neurohypophysectomized rats following chronic administration of vasopressin. J Neurosci 7:2564-2575.

Herman JP, Schafer MK-H, Watson SJ, Sherman TG (1991) In situ hybridization analysis of arginine vasopressin gene transcription using intron-specific probes. Mol Endocrinol 5:1447-1456.

Hevner RF, Wong-Riley MTT (1990) Regulation of cytochrome oxidase protein levels by functional activity in the macaque monkey visual system. J Neurosci 10:1331-1340.

Hevner RF, Wong-Riley MTT (1993) Mitochondrial and nuclear gene expression for cytochrome oxidase subunits are disproportionately regulated by functional activity in neurons. J Neurosci 13:1805-1819.

Jensen MB, González B, Castellano B, Zimmer J (1994) Microglial and astroglial reactions to anterograde axonal degeneration: a histochemical and immunocytochemical study of the adult rat fascia dentata after entorhinal perforant path lesions. Exp Brain Res 98:245-260.

Krisch B (1980) Electron microscopic immunocytochemical investigation on the postnatal development of the vasopressin system in the rat. Cell Tissue Res 453-471.

Landgraf R, Neumann I, Schwarzberg H (1988) Central and peripheral release of vasopressin and oxytocin in the conscious rat after osmotic stimulation. Brain Res 457:219-225. 
Lee M-Y, Hofmann H-D, Kirsch M (1997) Expression of ciliary neurotrophic factor receptor-alpha messenger RNA in neonatal and adult rat brain: an in situ hybridization study. Neuroscience 77:233-246.

MacLennan AJ, Vinson EN, Marks L, McLaurin DL, Pfeifer M, Lee N (1996) Immunohistochemical localization of ciliary neurotrophic factor receptor $\alpha$ expression in the rat nervous system. J Neurosci 16:621-630.

Mander TH, Morris JF (1994) Perivascular microglia in the rat neural lobe engulf magnocellular secretory terminals during osmotic stimulation. Neurosci Lett 180:235-238.

Mathern GW, Pretorius JK, Babb TL (1995) Quantified patterns of mossy fiber sprouting and neuron densities in hippocampal and lesional seizures. J Neurosurg 82:211-219.

McMahon SB, Kett-White R (1991) Sprouting of peripherally regenerating primary sensory neurones in the adult central nervous system. J Comp Neurol 304:307-315.

Moffett CW, Paden CM (1994) Microglia in the rat neurohypophysis increase expression of class I major histocompatibility antigens following central nervous system injury. J Neuroimmunol 50:139-151.

Molander C, Kinnman E, Aldskogius H (1988) Expansion of spinal cord primary sensory afferent projection following combined sciatic nerve resection and saphenous nerve crush: a horseradish peroxidase study in the adult rat. J Comp Neurol 276:436-441.

Morris JF, Dyball REJ (1974) A quantitative study of the ultrastructural changes in the hypothalamo-neurohypophysial system during and after experimentally induced hypersecretion. Cell Tissue Res 149:525-535.

Murray M (1993) Plasticity in the spinal cord: the dorsal root connection. Rest Neurol Neurosci 5:37-45.

Nakajima K, Kohsaka S (1993) Characterization of brain microglia and the biological significance in the central nervous system. Adv Neurol 60:734-743.

Neeper SA, Gómez-Pinilla F, Choi J, Cotman C (1995) Exercise and brain neurotrophins. Nature 373:109.

Neumann I, Landgraf R, Bauce L, Pittman QJ (1995) Osmotic responsiveness and cross talk involving oxytocin, but not vasopressin or amino acids, between the supraoptic nuclei in virgin and lactating rats. J Neurosci 15:3408-3417.

Nilaver G, Zimmerman EA, Wilkins J, Michaels J, Hoffman D, Silverman A-J (1980) Magnocellular hypothalamic projections to the lower brain stem and spinal cord of the rat. Neuroendocrinology 30:150-158.

Nixon BJ, Doucette R, Jackson P, Diamond J (1984) Impulse activity evokes precocious sprouting of nociceptive nerves into denervated skin. Somatosens Mot Res 2:97-126.

Noebels JL, Qiao X, Nahm WK (1997) Neurogenetic approaches to axon sprouting in the hippocampus. Adv Neurol 72:35-44.

Pearson RCA, Neal JW, Powell TPS (1987) Bilateral morphological changes in the substantia nigra of the rat following unilateral damage of the striatum. Brain Res 400:127-132.

Peterson RP (1966) Magnocellular neurosecretory centers in the rat hypothalamus. J Comp Neurol 128:181-190.

Prince DA, Salin P, Tseng GF, Hoffman S, Parada I (1997) Axonal sprouting and epileptogenesis. Adv Neurol 72:1-8.

Raisman G (1973) Electron microscopic studies of the development of new neurohaemal contacts in the median eminence of the rat after hypophysectomy. Brain Res 55:245-261.

Represa A, Tremblay E, Ben-Ari Y (1990) Sprouting of mossy fibers in the hippocampus of epileptic human and rat. Adv Exp Med Biol 268:419-424.

Represa A, Niquet J, Pollard H, Khrestchatisky M, Ben-Ari Y (1994) From seizures to neo-synaptogenesis: intrinsic and extrinsic determinants of mossy fiber sprouting in the adult hippocampus. Hippocampus 4:270-274.

Represa A, Niquet J, Pollard H, Ben-Ari Y (1995) Cell death, gliosis, and synaptic remodeling in the hippocampus of epileptic rats. J Neurobiol 26:413-425.

Salm AK, Hatton GI, Nilaver G (1982) Immunoreactive glial fibrillary acidic protein in pituicytes of the rat neurohypophysis. Brain Res 236:471-476.

Schoen SW, Kreutzberg GW (1994) Synaptic 5'-nucleotidase activity reflects lesion-induced sprouting within the adult rat dentate gyrus. Exp Neurol 127:106-118.

Seligman AM, Karnovsky MJ, Wasserkrug HL, Hanker JS (1968) Nondroplet ultrastructural demonstration of cytochrome oxidase activity with a polymerizing osmiophilic reagent, diaminobenzidine (DAB). J Cell Biol 38:1-14.

Sherman TG, Day R, Civelli O, Douglass J, Herbert E, Akil H, Watson SJ (1988) Regulation of hypothalamic magnocellular neuropeptides and their mRNAs in the Brattleboro rat: coordinate responses to further osmotic challenge. J Neurosci 8:3785-3796.

Silverman AJ, Zimmerman EA (1982) Adrenalectomy increases sprouting in a peptidergic neurosecretory system. Neuroscience 7:2705-2714

Silverman A-J, Zimmerman EA (1983) Magnocellular neurosecretory system. Annu Rev Neurosci 6:357-380.

Steward O (1994) Cholinergic sprouting is blocked by repeated induction of electroconvulsive seizures, a manipulation that induces a persistent reactive state in astrocytes. Exp Neurol 129:103-111.

Stringer JL, Agarwal KS, Dure LS (1997) Is cell death necessary for hippocampal mossy fiber sprouting? Epilepsy Res 27:67-76.

Summy-Long JY, Neumann I, Terrell ML, Koehler E, Gestl S, Landgraf R, Kadekaro M (1994) Crosstalk in the magnocellular system during osmotic stimulation of one supraoptic nucleus. Brain Res Bull 33:645-654

Sutula T, Xiao-Xian H, Cavazos J, Scott G (1988) Synaptic reorganization in the hippocampus induced by abnormal functional activity. Science 239:1147-1150.

Takano S, Negoro H, Honda K, Higuchi T (1990) Electrophysiological evidence for neural connections between the supraoptic nuclei. Neurosci Lett 111:122-126.

Thellier D, Moos F, Richard P, Stoeckel ME (1994) Evidence for connections between a discrete hypothalamic dorsochiasmatic area and the supraoptic and paraventricular nuclei. Brain Res Bull 34:261-274.

Theodosis DT, Poulain DA (1993) Activity-dependent neuronal-glial and synaptic plasticity in the adult mammalian hypothalamus. Neuroscience 57:501-535.

Thoenen H (1995) Neurotrophins and neuronal plasticity. Science 270:593-598.

Van Leeuwen FW, de Raay C, Swaab DF, Fisser B (1979) The localization of oxytocin, vasopressin, somatostatin and luteinizing hormone releasing hormone in the rat neurohypophysis. Cell Tissue Res 202:189-201.

Van Tol HHM, Voorhuis DThAM, Burbach JPH (1987) Oxytocin gene expression in discrete hypothalamic magnocellular cell groups is stimulated by prolonged salt loading. Endocrinology 120:71-76.

Verbalis JG (1993) Osmotic inhibition of neurohypophysial secretion. Ann NY Acad Sci 689:146-160.

Verbalis JG, Drutarosky MD (1988) Adaptation to chronic hypoosmolality in rats. Kidney Int 34:351-360.

Vutskits L, Bartanusz V, Schulz M-F, Kiss JZ (1998) Magnocellular vasopressinergic neurons in explant cultures are rescued from cell death by ciliary neurotrophic factor and leukemia inhibiting factor. Neuroscience 87:571-582.

Watt JA, Paden CM (1991) Compensatory sprouting of uninjured magnocellular neurosecretory axons in the rat neural lobe following unilateral hypothalamic lesion. Exp Neurol 111:9-24.

Windle RJ, Judah JM, Forsling ML (1995) Do vasopressin and oxytocin have synergistic renal effects in the conscious rat? J Endocrinol 144:441-448.

Wong-Riley M, Riley DA (1983) The effect of impulse blockage on cytochrome oxidase activity in the cat visual system. Brain Res 261:185-193.

Wong-Riley MTT (1976) Endogenous peroxidatic activity in brain stem neurons as demonstrated by their staining with diaminobenzidine in normal squirrel monkeys. Brain Res 108:257-278.

Wong-Riley MTT (1989) Cytochrome oxidase: an endogenous metabolic marker for neuronal activity. Trends Neurosci 12:94-101.

Wong-Riley MTT, Walsh SM, Leake-Jones PA, Merzenich MM (1981) Maintenance of neuronal activity by electrical stimulation of unilaterally deafened cats demonstratable with cytochrome oxidase technique. Ann Otol Rhinol Laryngol 90:30-32.

Woolf CJ, Reynolds ML, Molander C, O'Brien C, Lindsay RM, Benowitz LI (1990) The growth-associated protein GAP-43 appears in dorsal root ganglion cells and in the dorsal horn of the rat spinal cord following peripheral nerve injury. Neuroscience 34:465-478.

Zhou X, Herman JP, Paden CM (1997) Expression of insulin-like growth factor binding protein-2 during postnatal development of the rat neurointermediate pituitary. Neuroendocrinology 66:17-27. 